\title{
Modeling Workload, Job Satisfaction, Work Stress and Organizational Commitment on Turnover Intention: Evidence from Hospitality Management Educators
}

\author{
Mark Lixcel Q. Lantican \\ Far Eastern University, Manila, Philippines \\ Email: mlantican@feu.edu.ph
}

How to cite this paper: Lantican, M. L. Q (2021). Modeling Workload, Job Satisfaction, Work Stress and Organizational Commitment on Turnover Intention: Evidence from Hospitality Management Educators. Journal of Human Resource and Sustainability Studies, 9, 439-450.

https://doi.org/10.4236/jhrss.2021.93028

Received: March 31, 2021

Accepted: September 10, 2021

Published: September 13, 2021

Copyright $\odot 2021$ by author(s) and Scientific Research Publishing Inc. This work is licensed under the Creative Commons Attribution International License (CC BY 4.0).

http://creativecommons.org/licenses/by/4.0/

\begin{abstract}
This study was conducted to describe and measure the factors influencing faculty members' workload, job satisfaction, work stress, organizational commitment, and turnover intentions in hospitality education. To achieve this goal, 400 hospitality management educators of both public and private tertiary educational systems in NCR were selected through purposive-quota sampling. A semi-structured questionnaire and focus group discussion were used to collect data from the participants. Descriptive statistics including mean, standard deviation and rank and Inferential statistics including independent t-test, One Way Analysis of Variance and Pearson-r were employed to analyze quantitative data, while qualitative data was analyzed according to themes. Generally, women are independently capable of sharing their reliable and professional assessments. It was also shown that the faculty members are presently contented with their teaching jobs and did not express agreement on whatever reason to leave. They find their workloads in school manageable and are willing to provide engaging instruction to meet their students' needs through various modalities and instructional materials as they are contented with their jobs. Adversely, they differ in consensus on the five-stated variables when grouped in the length of stay and tenure status. New and old faculty members and regular full-time instructors and lecturers, together with the regular part-time instructors and lecturers, share a similar degree of unanimity regarding workload, job satisfaction, work stress, organizational commitment, and turnover intent. The Structural Equation Modeling (SEM) analysis includes the path directions and relationship between descriptive statistics, structural model evaluation, and the five variables. As a result, it was proven in this study that Organizational Commitment and Job Satisfaction, having significant covariance, have a significant direct effect on turnover intention.
\end{abstract}




\section{Keywords}

Workload, Job Satisfaction, Work Stress, Organizational Commitment, Turnover Intention, Hospitality Management Educators

\section{Introduction}

Most countries around the world have temporarily closed educational institutions to contain the spread of the COVID-19 pandemic and reduce infections (UNESCO, 2020). This closure has affected more than 1.2 billion learners worldwide with more than 28 million learners in the Philippines (UNESCO, 2020). Responses like community lockdown and community quarantine of several countries have led students and educators to study and work from home which led to the delivery of online, blended and modular learning platforms (Crawford et al., 2020). In addition, COVID-19 pandemic has significantly changed the educational system especially the status of educators. According to Toquero (2020), faculty members are trying their best to make the students' learning journey as worthwhile and meaningful as possible in this time of the pandemic. They are compliant with the school administration's directive of producing instructional materials with so little time given and complied without compromising the health and wellness.

As a result of the large impact of COVID-19 on education sector, many educators both in public and private institutions have lost their source of income, temporarily or permanently, or otherwise suffered a reduced income. Retained educators who do not receive regular wage and whose working hours were reduced on account of the adoption of flexible work arrangements including reduction of work hours or work days, rotation of workers, forced leave, etc. by their employers, resulting in reduced income (MacKenzie, 2020). According to Philippine Statistics Authority (2020), among the employed persons in educator sector who were not at work, the majority (97.0\%) expressed that their reason for not being at work was due to the COVID-19 pandemic, and community quarantine. This was followed by the variable working time or nature of work at 1.1 percent, other reasons specified at 0.8 percent, low or off season at 0.3 percent, and health or medical limitations at 0.2 percent.

The researcher has learned from experience that some faculty members, especially those in the private sector, tolerate the high workload but with unjust compensation from their respective academic institutions. There are also reports that even with increased workload caused by accreditation, teacher shortage, competitions, community service, and other extracurricular activities, faculty members are taking such additional assignments. Inline, the researcher argues for identifying their willingness to stay in the academe and the factors affecting their intention. Now, based on the researcher's initial review of related literature, it was found out that no study has been conducted on this topic, particularly con- 
cerning faculty members from the hospitality education.

Several factors may affect employee retention in an institution (Wang \& Yuan, 2018). According to Azanza et al. (2015), the turnover intention is the mobility of employee turnover, reflecting the quality and quantity of their alternatives and their degree of job satisfaction. Losing employees through turnover is costly, with concerns involving separation, loss of productivity, recruitment, interviewing, training, and onboarding. There are different reasons employees think of leaving an academic organization to pursue another job opportunity with other institutions or careers, which has a more straightforward path for upward progression (Huber, 2018). Turnover intention gives a new perspective and may imply that even satisfied employees can leave their jobs. An increase in leadership behavior would also mutually oppose the decrease in the faculty's turnover intention; organizational commitment would likely reduce the faculty's turnover intention; and improved workplace fairness would also likely fall turnover intention of faculty (De La Peña, 2018). Program Heads should know how a faculty makes choices and understand their behavior. When evaluating the need to investigate the satisfaction and commitment of faculty members, one must consider the collaborative working environment, which could be driven by workload, job satisfaction, work stress, and organizational commitment. Despite the excellent work revealing workload inequities and consequences, few studies have examined the conditions and practices within which workload is perceived as more or less fair (O'Meara et al., 2019) and reflects low job satisfaction (Osifila \& Aladetan, 2020). Work Stress is a widespread problem and has become a significant public health issue due to its adverse effects on physiological and mental health (Lee, Joo, \& Choi, 2013).

Recognizing that this COVID-19 pandemic has immensely impacted the education sector, the conduct of this research is vital information on the faculty members' experiences and conditions. Inline, possible recommendations that will help promote sound decision-making of school matters directly affect faculty instruction, online class management, and work-life balance during this pandemic.

\section{Methodology}

This study is a causal research investigating the relationships between the respondents' demographic profile and the theories, namely workload, job satisfaction, work stress, and organizational commitment towards turnover intent by Hospitality Management Educators in National Capital Region. In this study, the triangulation method was used for better application and evaluation of the research. Through triangulation, the researcher acquired qualitative and quantitative data, and the analysis of these increased the trustworthiness or validity. The researcher used sequential explanatory design by collecting and analyzing quantitative data and then qualitative data in two consecutive phases within one study (Figure 1). The researcher interpreted how the qualitative results explain the 


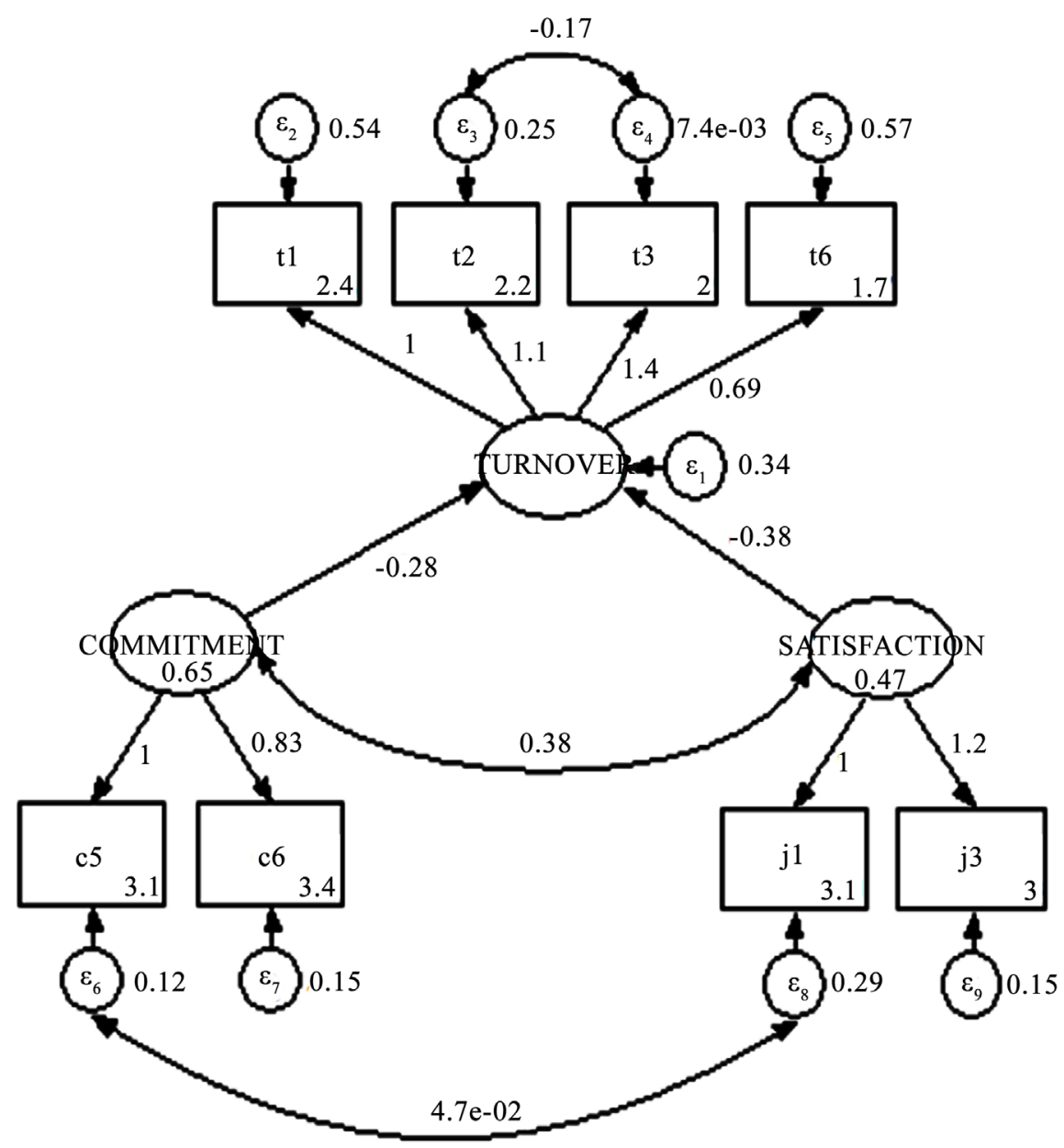

Figure 1. Emerging model of the causal relationships between organizational commitment and job satisfaction towards turnover intention fitted structural equation model (SEM).

quantitative results, thereby expounding upon the findings of one method with another method.

The setting of this research study is online, both synchronously and asynchronously. The context for this research study included public and private colleges and universities offering a degree in Hospitality Management with the intended participant being full-time or part-time faculty members. The researcher has taken advantage of purposive random sampling whereas a ratio of 10 respondents to 1 variable which was desired as having the exact ratio in this study which is 40 variables. Hence, 400 faculty members were bounded by the criteria that all participants were currently employed either at a public or a private college or University, either full-time or part-time, in the National Capital Region (NCR).

The researcher used an online questionnaire. To measure the workload, the researcher took advantage of getting an idea on a workload scale of eight questions from CHED's guidelines on the implementation of flexible delivery of student affairs and services during the COVID-19 pandemic. To measure the work- 
load, the researcher took advantage of getting an idea on a workload scale of eight questions from CHED's guidelines on implementing flexible delivery of student affairs and services during the COVID-19 pandemic. For scaling workload, sample items contained "I can achieve the course learning outcomes and assess student performance in an online, remote learning environment". Job satisfaction was measured by questions like "I am satisfied with how my immediate head takes care of the employees/complaints". The researcher measured stress in which sample items contained "I am carrying out school duties during the time dedicated to my family (e.g., to read and mark offhand papers at home)". The organizational commitment was measured with eight items, including items such as "I am extremely glad that I chose this organization". Lastly, the Turnover intention was measured by questions like "I no longer have a good degree to which I am able to maintain a positive learning climate for students".

For the qualitative part of the study, the researcher used focus group discussion comprised of 10 people who provided information or knowledge of a topic following an interview protocol. Due to social distancing being observed due to COVID 19 pandemic, the researcher utilized the online conferencing tool Zoom to conduct synchronous online focus group interviews which has lasted for an hour. The focus group interview was audio recorded as an internal function of the synchronous online conferencing too.

Descriptive and inferential statistics were used in the quantitative part of the study to analyze the data included measures such as frequencies, mean, percentages, ranking, Analysis of variance (ANOVA), independent t-test, Pearson Chi-squared and Structural Equation Modeling for the proposed model. Based on the results of the qualitative data and the subsequent development of qualitative focus group questions, the researcher used thematic analysis.

\section{Results}

Table 1 shows the demographic profile of the respondents, majority (62\%) of them are females. The gender ratio is about 3 female faculty members for every 2 male faculty members (5:3). An equal majority (about $33 \%$ each) of them are about 31 - 40 years old and about 41 - 50 years old. On the average, the respondents are approximately 44 years old. Majority (or 65\%) have completed and earned their Master's degrees, 92 (or 23\%) have finished their doctorate course while 8 (or $2 \%$ ) continued to take post-doctorate courses. The remaining 40 faculty-respondents (10\%) have yet to enroll and take post-graduate courses. Majority (about 56\%) have been teaching for about 10 semesters and above. Majority (about 58\%) are regular full-time faculty members of their respective educational institutions.

Table 2 shows the dimensions of why the respondents intend to stay. It reveals that they expressed disagreement on their intention based on the assessment on their turnover intention. Intention to stay within the next school year (item 3) yielded with the lowest followed by giving opportunities to achieve 
Table 1. Demographic profile of the respondents.

\begin{tabular}{|c|c|c|}
\hline Educational Attainment & Frequency (f) & Percentage (\%) \\
\hline Bachelor's Degree & 40 & 10.0 \\
\hline Master's Degree & 260 & 65.0 \\
\hline Doctorate & 92 & 23.0 \\
\hline Post Doctorate & 8 & 2.0 \\
\hline Total & 400 & 100.0 \\
\hline No. of Semesters & Frequency $(\mathrm{f})$ & Percentage (\%) \\
\hline 3 or Less & 66 & 16.5 \\
\hline $4-6$ & 67 & 16.8 \\
\hline $7-9$ & 42 & 10.5 \\
\hline 10 and Above & 225 & 56.3 \\
\hline Total & 400 & 100.0 \\
\hline Tenure Status & Frequency $(\mathrm{f})$ & Percentage (\%) \\
\hline Regular Full-Time & 230 & 57.5 \\
\hline Regular Part-Time & 36 & 9.0 \\
\hline Full-Time Lecturer & 55 & 13.8 \\
\hline Part-Time Lecturer & 79 & 19.8 \\
\hline Total & 400 & 100.0 \\
\hline
\end{tabular}

Table 2. Respondents' assessment in regard turnover intention. (Dimensions for their intent to stay).

\begin{tabular}{|c|c|c|c|}
\hline Indicators & WM & Interpretation & Rank \\
\hline 1. I ask other co-worker to stay in our current post. & 2.49 & Disagree & 2 \\
\hline 2. My current job is addressing my important personal needs. & 2.47 & Disagree & 3 \\
\hline 3. I intend to stay in my career within the next school year. & 2.04 & Disagree & 8 \\
\hline 4. If I could choose again, I would work for this organization. & 2.29 & Disagree & 5 \\
\hline $\begin{array}{l}\text { 5. This organization gives me opportunities to achieve my } \\
\text { professional growth. }\end{array}$ & 2.05 & Disagree & 7 \\
\hline 6. I felt appreciated by my supervisor. & 2.28 & Disagree & 6 \\
\hline 7. I am satisfied with my salary compared to what I do. & 2.30 & Disagree & 4 \\
\hline $\begin{array}{l}\text { 8. I have good degree to which I am able to maintain a positive } \\
\text { learning climate for students. }\end{array}$ & 2.79 & Agree & 1 \\
\hline Overall Weighted Mean & 2.33 & Disagree & \\
\hline
\end{tabular}

professional growth by the organization yielded as second to the lowest. Other disagreements including appreciation by supervisor and salary satisfaction. However, the respondents revealed that although they implied intention to leave their current post, they disclosed that they have good degree which maintains their positive learning climate for the students (item 8 ) which rank as the highest. In 
summary, all the respondents have negative feelings with regards to turnover intention based on their assessment. The results imply that they are presently not contented with their teaching jobs and express agreement on whatever reason to leave their current post.

Table 3 shows the level of agreement of the respondents in regard the various domains (variables): the respondents have "strongly agreed" in regard their workloads as revealed by the overall weighted mean of 3.47 suggesting that they find their workloads in school manageable. The respondents "agree" and are seen to be "satisfied" with their jobs as shown in the composite weighted mean of 2.95. The respondents "strongly agree" on the work stress they encounter in this period of pandemic due to the "new normal" of teaching-learning. This is revealed by the overall weighted mean of 3.34. The respondents "strongly agree"

Table 3. Significant difference in the level of agreement of faculty members as regards the various domains considered in terms of demographic profile.

\begin{tabular}{|c|c|c|c|}
\hline Indicators & $p$-value & Decision & Interpretation \\
\hline \multicolumn{4}{|l|}{ Workload } \\
\hline Sex & 0.350 & Accept Hypothesis & Not Significant \\
\hline Age & 0.24 & Accept Hypothesis & Not Significant \\
\hline Educational Attainment & 0.151 & Accept Hypothesis & Not Significant \\
\hline Length of Stay & 0.076 & Accept Hypothesis & Not Significant \\
\hline Tenure Status & 0.380 & Accept Hypothesis & Not Significant \\
\hline \multicolumn{4}{|l|}{ Job Satisfaction } \\
\hline Sex & 0.001 & Reject Hypothesis & Significant \\
\hline Age & 0.121 & Accept Hypothesis & Not Significant \\
\hline Educational Attainment & 0.338 & Accept Hypothesis & Significant \\
\hline Length of Stay & 0.005 & Reject Hypothesis & Not Significant \\
\hline Tenure Status & 0.239 & Accept Hypothesis & Not Significant \\
\hline \multicolumn{4}{|l|}{ Work Stress } \\
\hline Sex & 0.607 & Accept Hypothesis & Not Significant \\
\hline Age & 0.018 & Reject Hypothesis & Significant \\
\hline Educational Attainment & 0.606 & Accept Hypothesis & Not Significant \\
\hline Length of Stay & 0.006 & Reject Hypothesis & Significant \\
\hline Tenure Status & 0.076 & Accept Hypothesis & Not Significant \\
\hline \multicolumn{4}{|l|}{ Organizational Commitment } \\
\hline Sex & 0.000 & Reject Hypothesis & Significant \\
\hline Age & 0.039 & Reject Hypothesis & Significant \\
\hline Educational Attainment & 0.173 & Accept Hypothesis & Not Significant \\
\hline Length of Stay & 0.018 & Reject Hypothesis & Significant \\
\hline Tenure Status & 0.864 & Accept Hypothesis & Not Significant \\
\hline
\end{tabular}


on their organizational commitment to their respective organizations as indicated by the overall weighted mean of 3.33. Overall, Workload yielded with the highest composite mean of 3.47 and interpretation of strongly agree followed by work stress of 3.34 and strongly agree and organizational commitment of 3.33 and strongly agree while job satisfaction yielded with the lowest composite mean of 2.95 with interpretation of agree.

Table 4 shows the results of the independent t-Test and the one-way Analysis of Variance (ANOVA) which reveal that in regard to workload, all the demographic profile indicators do not have relationship with workload; in regard to job satisfaction, only the sex and length of stay have significant relationship with job satisfaction $(p$-value $=0.018 ; p$-value $=0.006)$; in regard to work stress, only the age and length of stay with work stress $(p$-value $=0.001 ; p$-value $=0.005)$; and in terms of organizational commitment, sex, age and length of stay have significant relationship with organizational commitment $(p$-value $=0.000 ; p$-value $=0.039 ; p$-value $=0.018$ )

With regard to the significant relationship between the respondents' level of agreement on the turnover intent and the various domains (or variable) considered in this study reveal that a correlation for the data showed that the respondents' intent to leave their teaching jobs is not significantly related to their workload, $r=0.096, \mathrm{n}=400, p>0.05$, two-tails. Therefore, the null hypothesis states that there is no significant relationship between the respondents' level of agreement on the turnover intent and workload is accepted at $\varepsilon=0.05$. Similarly, there is no significant correlation between turnover intent and work stress, $r=$ $-0.068, \mathrm{n}=400, p>0.05$, two-tails. Hence, the null hypothesis states that there is no significant relationship between the respondents' level of agreement on the turnover intent and work stress is likewise accepted at $\varepsilon=0.05$. Contrastingly, turnover intent significantly correlates with job satisfaction, $r=0.571, \mathrm{n}=400, p$ $<0.05$, two-tails. With the result, the null hypothesis states that there is no significant relationship between the respondents' level of agreement on the turnover intent and job satisfaction is rejected at $\varepsilon=0.05$. Lastly for the respondents, turnover intent significantly correlates with commitment to the institution, $r=$ $0.436, \mathrm{n}=400, p<0.05$, two-tails. Subsequently, the null hypothesis states that there is no significant relationship between the respondents' level of agreement on the turnover intent and organizational commitment is again rejected at a = 0.05 .

Table 4. Significant relationship between the respondents' level of agreement on turnover intent and the various domains (variables) considered.

\begin{tabular}{cccc}
\hline Indicators & $p$-value & Decision & Interpretation \\
\hline Turnover Intent vs. Workload & 0.540 & Accept Hypothesis & Not Significant \\
Turnover Intent vs. Job Satisfaction & 0.000 & Reject Hypothesis & Significant \\
Turnover Intent vs. Work Stress & 0.175 & Accept Hypothesis & Not Significant \\
$\begin{array}{c}\text { Turnover Intent vs. Organizational } \\
\text { Commitment }\end{array}$ & 0.000 & Reject Hypothesis & Significant
\end{tabular}


With regard to Model for the Faculty's Behavior of their Intent to Stay, Figure 1 shows that the observed variables $\mathrm{t} 2$ (My current job is not addressing my important personal needs) and $\mathrm{t} 3$ (I intend to look for a new career within the next school year) have significant covariance which shows significant relationship between each other. Also, c5 (For me, this is the best possible organization for which to work) and $\mathrm{j} 1$ ( $\mathrm{I}$ am being paid a fair amount for the work I do) have significant covariance. Based on EFA, organizational commitment is significantly predicted by $\mathrm{c} 5$ (For me, this is the best possible organization for which to work) and c6 (I am extremely glad that I chose this organization to work for others I was considering at the time I joined); job satisfaction is significantly predicted by $j 1$ ( $\mathrm{I}$ am being paid fair amount for the work I do) and j3 (I am satisfied with the benefits I receive); and turnover intention is significantly predicted by $\mathrm{t} 1$ (I intend to ask other people about new job opportunities), t2 (My current job is not addressing my important personal needs), $\mathrm{t} 3$ (I intend to look for a new career within the next school year), and t6 (I felt unappreciated by my faculty supervisor).

After all data collection pieces were collected and transcribed among the respondents through focus group discussion, significant statements were identified. Each of those significant statements was coded, and from the codes, two interwoven themes emerged. They are: 1) the role and extent of involvement of educators during new normal; and 2) problems and challenges encountered by the educators during new normal.

The theme the role and extent of involvement of educators during new normal emerged because as educators, they assume an important role in the higher education institutions (HEIs). They are primarily responsible for ensuring that an adequate learning environment is established for learners within the community. This theme did not simply emerge from answering the questions. It was evident on their shared experiences. This theme consists of two subthemes including as module developer and facilitator of learning using online modality. It was revealed in the experiences of the HEIs educators that they do not have any choice but to develop and write modules for the students as it is needed during new normal form of education, and it is part of their job description. Also, the results revealed that despite of the effect of pandemic in the educational system, still, an educator is an educator no matter how hard the situation and no matter how difficult to attend the needs of the learners.

In addition to the understanding of experiences of educators during new normal form of education, the problems and challenges encountered by the educators was a theme which emerged from among the data. This theme did not simply emerge from answering the questions. It was evident on their shared experiences. This theme consists of two subthemes including overworked and additional workload; and expenses; and lack of enrollees and being underpaid. The respondents revealed that in fulfilling their role as education in HEIs, during new normal it resulted to being overworked. The respondents revealed during the interview their sentiments on the implications of adapting to new normal which resulted to more 
tasks and works. Another problem and challenge that the respondents emerged from their experiences is the lack of enrollees and being underpaid.

\section{Discussions}

Based on the aforementioned results, there are more women than men faculty members teaching in the hospitality education, mostly middle-aged adults, possessing the appropriate educational qualification making them eligible to teach, has been teaching for about 10 semesters and above and are mostly regular full-time teachers during the school year 2019-2020. They are individuals who are independently capable to share their reliable and professional assessments in regard work load, job satisfaction, work stress, organizational commitment and turnover intentions.

In addition, the faculty members are presently moderately contented with their teaching jobs and express agreement on whatever reason to leave their current post. Aside from monetary benefits/rewards, they express moderate willingness to continue teaching because it is more of a continuous learning experience for them and further extend their knowledge as well as articulate their love for interacting and engaging with other people. However, respondents revealed the need for higher salary and benefits this time of new normal. Although they have been experiencing work stress, they find their workloads in school manageable and are willing to provide engaging instruction and meet the needs of their students through various modalities and instructional materials as they are contented with their jobs. Female and male faculty members concur with their agreement as regards workload and work stress.

However, they differ in their level of agreement in regard to job satisfaction, organizational commitment and turnover intent. Regardless of age, the faculty members share the same level of agreement as to their work load and job satisfaction. In contrast, they do not conform in terms of work stress, organizational commitment and turnover intent. Despite differences in educational attainment, the faculty members expressed the same degree of concurrence in their work load, job satisfaction, work stress, organizational commitment and turnover intent. Contrastingly, they differ in consensus on the five-stated variables when they are grouped in terms of length of stay and tenure status. That is, new and old faculty members as well as the regular full-time instructors and lecturers together with the regular part-time instructors and lecturers share similar degree of unanimity. Having a mean residual of 0 across all observed variables confirms that the model is white noise which implies that fit of the model is excellent.

As per limitation of this paper, this research focused on the demographic profile of hospitality educators. It is endorsed for continued research in this area and adaption to the industry. As a new and evolving field of practice and study, the literature review found nothing explicitly addressing faculty job satisfaction, workload, work stress, organizational commitment, or turnover intentions at the tertiary level, especially in the private sector. 
This research study utilized a purposive sample, which was criticized for facilitating systematic bias, wherein the results may not generalize and cannot speak for the whole institute, so the study's external validity can be compromised. Along the same lines, the study's research design is further limited by using a self-report instrument, in which participants may over or under-report a phenomenon. Finally, the study could lack the component of follow-up, in which the researcher can compare participants' turnover intentions (stay or leave) versus their actual turnover actions.

Thus, the following are the recommendations of the study including school administrators and the academe ought to coordinate with the CHED and use their first-hand experience to tweak the current modular program to lessen the burden of the teachers. In the encoding, printing, sorting and distributing of the modules; while at the same time improving the production process to lessen the government's expenditures on paper, ink and other print materials. In consideration of the COVID-19 pandemic and the minimum health standards made known to the public, the use of paper, and other COVID susceptible materials must be eliminated from the equation as much as possible. It is also recommended to revamp the course for the future semesters. The first is to reexamine the course learning objectives as it may be too much in a remote learning setting. The second is paring down the learning outcomes to the truly essential but providing students with avenues to pursue areas of interest. This study encourages faculty members to assign a mentor to new hires as soon as they regain their enrollment; however, this study does not clarify which mentoring model will have the most significant effect on faculty retention. Mentoring may include co-teaching an online course with an experienced online. Further research is needed to study and analyze schools' mentoring models with successful distance learning set up to identify the most significant components and practices that can then be disseminated. Future research should investigate specific models, frequencies, durations, and mediums of mentorship in the distance learning environment to support faculty members and mentors in designing mentorship programs that positively affect distance learning practices and student learning outcomes. An essential component, which this study lacked, is a follow-up in which the researchers could compare participants' turnover intentions versus the attrition rate. As more longitudinal data concerning faculty members beginning to emerge, careful attention should be paid to faculty members' attrition. It would be worth comparing the attrition of faculty members, particularly those hired as schools regained their enrollees, concerning traditional faculty attrition. Furthermore, it is advised for future researchers to enhance the proposed model to further investigate the relationships between demographic profile and faculty members' workload, job satisfaction, work stress and organizational commitment towards turnover intention.

\section{Conflicts of Interest}

The author declares no conflicts of interest regarding the publication of this paper. 


\section{References}

Azanza, G., Moriano, J. A., Molero, F., \& Mangin, J.-P. L. (2015). The Effects of Authentic Leadership on Turnover Intention. Leadership \& Organization Development Journal, 36, 955-971. https://doi.org/10.1108/LODJ-03-2014-0056

Crawford, J., Butler-Henderson, K., Jurgen, R., Malkawi, B. H., Glowatz, M., Burton, R., Magni, P., \& Lam, S. (2020). COVID-19: 20 Countries' Higher Education Intra-Period Digital Pedagogy Responses. Journal of Applied Learning \& Teaching, 3, 9-28. https://doi.org/10.37074/jalt.2020.3.1.7

De La Peña, T. K. (2018). A Path Model of Turnover Intention among Teachers in Region XI. Tin-aw, 2. http://ejournals.ph/form/cite.php?id=13612

Huber, A. (2018). Staff Attrition vs. Staff Turnover: What's the Difference? Jobzology. https://jobzology.com/staff-attrition-vs-staff-turnover-whats-the-difference/

Lee, J.-S., Joo, E.-J., \& Choi, K.-S. (2013). Perceived Stress and Self-Esteem Mediate the Effects of Work-Related Stress on Depression. Stress and Health, 29, 75-81.

https://doi.org/10.1002/smi.2428

MacKenzie, K. (2020). An Exploration of the Factors Influencing Career Choice in Mental Health. Journal of Clinical Nursing, 29, 3764-3773.

https://doi.org/10.1111/jocn.15406

O’Meara, K., Lennartz, C. J., Kuvaeva, A., Jaeger, A., \& Misra, J. (2019). Department Conditions and Practices Associated with Faculty Workload Satisfaction and Perceptions of Equity. The Journal of Higher Education, 90, 744-772.

https://doi.org/10.1080/00221546.2019.1584025

Osifila, G. I., \& Aladetan, T. A. (2020). Workload and Lecturers' Job Satisfaction in Adekunle Ajasin University, Akungba-Akoko, Ondo State, Nigeria. Journal of Education and Learning (EduLearn), 14, 416-423. https://doi.org/10.11591/edulearn.v14i3.16140

Philippine Statistics Authority (2020) Employment Situation in July 2020. https://psa.gov.ph/content/employment-situation-july-2020

Toquero, C. M. (2020). Challenges and Opportunities for Higher Education amid the COVID-19 Pandemic: The Philippine Context. Pedagogical Research, 5, Article No. em0063. https://doi.org/10.29333/pr/7947

UNESCO (2020). COVID-19 and Higher Education: Today and Tomorrow Impact Analysis, Policy Responses and Recommendations. International Institute for Education Superior in Latin America and Caribbean.

https://www.guninetwork.org/publication/report-covid-19-and-higher-education-toda y-and-tomorrow-impact-analysis-policy-responses

Wang, Y., \& Yuan, H. (2018). What Is behind High Turnover: A Questionnaire Survey of Hospital Nursing Care Workers in Shanghai, China. BMC Health Services Research, 18, Article No. 485. https://doi.org/10.1186/s12913-018-3281-9 